\title{
Epidemiological analysis in support of hypothesis that D614G virus mutation is a major contributing factor to chemosensory dysfunction in COVID-19 patients
}

\author{
Anna See ${ }^{1,2}$ (ID $\cdot$ Karrie Kwan Ki Ko ${ }^{3}$ Song Tar Toh ${ }^{1,2}$ \\ Received: 10 June 2021 / Accepted: 11 June 2021 / Published online: 29 June 2021 \\ ○ The Author(s), under exclusive licence to Springer-Verlag GmbH Germany, part of Springer Nature 2021
}

\section{Dear Editor,}

We read with gratitude the letter by Bartheld et al. which attempted to elucidate the scientific reason underlying our team's observations in our previous publication $[1,2]$. Bartheld et al. correctly highlighted that the overall prevalence of anosmia in our study population ( $91 \%$ being Indians and Bangladeshis, or of South Asian descent) was low, at only $3.0 \%$. He proposed that the reason for this observation was due to the relative dominant prevalence of the D614 variant in earlier part of 2020 and went on to explain the molecular pathology for smell disturbance amongst the COVID-19 viral variants.

In view of his proposition, we undertook an epidemiological analysis with the Singapore General Hospital Department of Molecular Pathology and wish to present our findings which support Bartheld et al.'s proposition.

A retrospective epidemiological analysis of publicly available SARS-CoV-2 genomes in Singapore, from Feb 2020 to Apr 2021, downloaded from the Global Initiative on Sharing All Influenza Data (GISAID) was performed [3]. While we are clearly unable to map every study participant's genome to their smell status as this is a retrospective analysis, the following bar graph illustrates that a predominance

This reply refers to the comment available online at https://doi.org/ 10.1007/s00405-021-06759-9.

Anna See

anna.see.xinyin@singhealth.com.sg

1 Department of Otorhinolaryngology-Head and Neck Surgery, Singapore General Hospital, Academia, Level 5, 20 College Road, 169856 Singapore, Singapore

2 Surgery Academic Clinical Program, SingHealth, Singapore, Singapore

3 Department of Molecular Pathology, Singapore General Hospital, Singapore, Singapore of D614 was indeed observed in Singapore's SARS-CoV-2 genomes up to Aug 2020, after which the D614G mutation replaced the predominant variant type to become G614 (Fig. 1). From Apr 2020 to Sep 2020, over 95\% of all recorded COVID-19 cases in Singapore were from our South Asian foreign worker population [4]. Hence, it is reasonable to extrapolate that the predominance of D614 genome observed up till Aug 2020 was attributed to the South Asian foreign worker outbreak in Singapore. This group of patients was exactly our study's sample population.

However, while our findings confirm Bartheld's proposition that a predominance of D614 was observed in Singapore up till Aug 2020, we wish to highlight that Singapore's approach of aggressive mass testing to maximally detect all patients (including asymptomatics and pre-symptomatics) is also likely a contributing factor for our low observed anosmia rates. Future studies undertaken in a new world of endemic COVID-19 may be able to shed light on the true prevalence of olfactory dysfunction in COVID-19.

Author contributions All authors contributed to the letter conception and design.

Funding No funding was obtained. 
SARS-CoV-2 Spike protein mutation at amino acid position 614 , Singapore

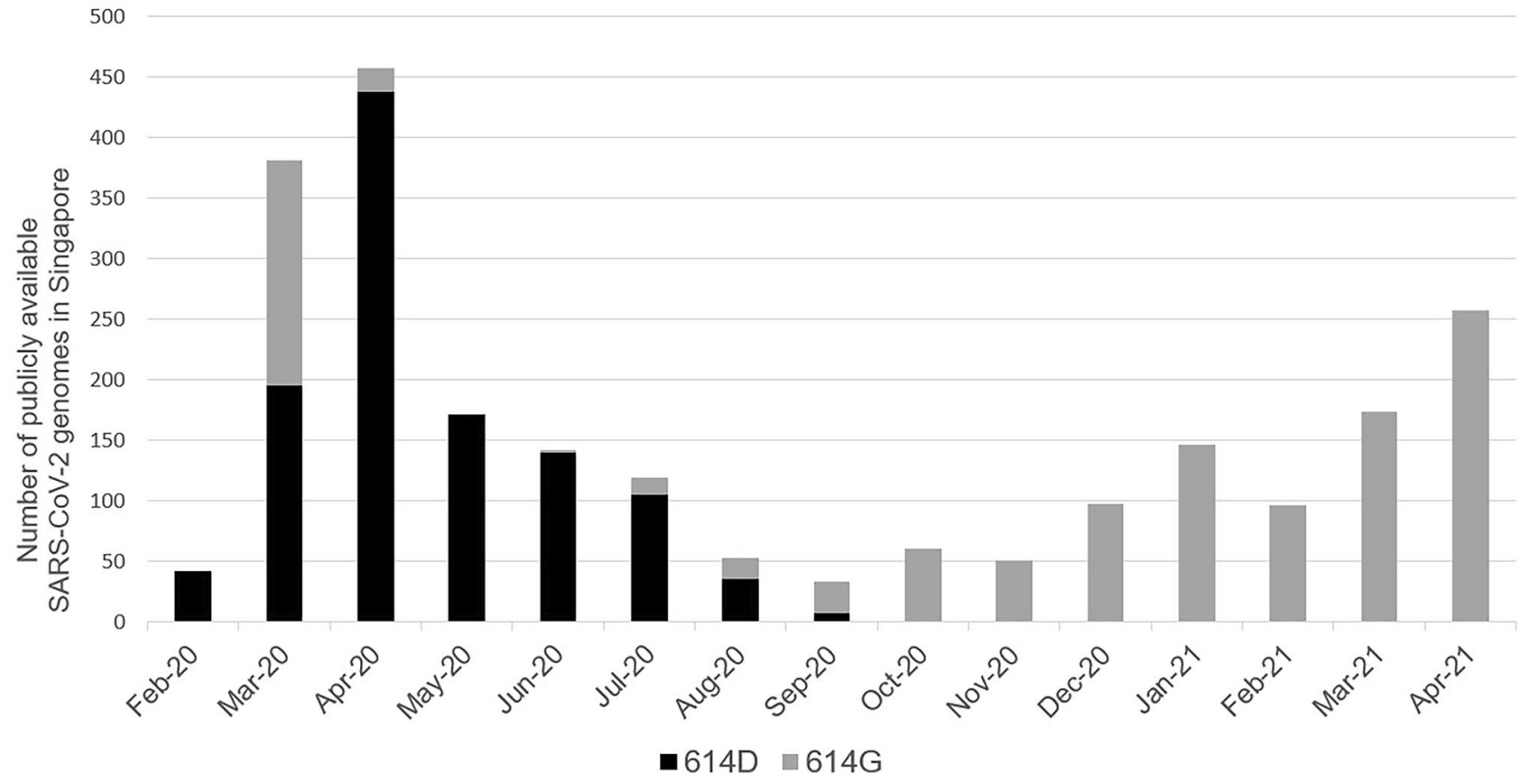

Fig. 1 Prevalence of SARS-CoV-2 spike protein mutation at amino acid position 614 amongst publicly available viral genomes in Singapore, from Feb 2020 to Apr 2021

\section{Declarations}

Conflicts of interest The authors declare that they have no conflicts of interests.

\section{References}

1. Soh SHL, See A, Teo NWY et al (2021) Prevalence of olfactory and taste dysfunction in COVID-19 patients: a community care facility study. Eur Arch Otorhinolaryngol. https://doi.org/10.1007/ s00405-021-06647-2

2. von Bartheld CS, Mathew D, Butowt R (2021) New study on prevalence of anosmia in COVID-19 implicates the D614G virus mutation as a major contributing factor to chemosensory dysfunction. Eur Arch Otorhinolaryngol. https://doi.org/10.1007/ s00405-021-06759-9

3. GISAID. Global Initiative on Sharing All Influenza Data. Available at: https://www.epicov.org/epi3/frontend\#331d16. Accessed 5 Apr 2021

4. Ministry of Health Singapore. Updates on COVID-19 (Coronavirus Disease 2019) local situation. Available at: https://www.moh. gov.sg/covid-19. Accessed 5 Jun 2021

Publisher's Note Springer Nature remains neutral with regard to jurisdictional claims in published maps and institutional affiliations. 